\title{
College Philosophy and Teaching
}

\author{
John Nikolaros ${ }^{1,2, *}$ \\ ${ }^{1}$ Harry S. Truman College, Chicago City Colleges, Chicago, USA \\ ${ }^{2}$ University of Phoenix, USA \\ *Correspondence: University of Phoenix, USA. E-mail: nikolarosj@email.phoenix.edu
}

Received: December 25, $2014 \quad$ Accepted: January 24, 2015 Online Published: February 13, 2015

doi:10.5430/wje.v5n1p144

URL: http://dx.doi.org/10.5430/wje.v5n1p144

\begin{abstract}
This article delineates critical practices for effective college teaching and learning. In addition, the author contends an internal transformation in philosophy, to facilitate a better college teaching environment. Moreover, a review and adaptation of Socratic paradigm techniques are included. The author outlines specific instructional and curricular facilitation modes for advanced learners.
\end{abstract}

Keywords: philosophy; pedagogy; andragogy

\section{Introduction}

As students achieve progressively higher curricula proficiencies, the methods and perplexities of teaching college students should also undertake examination. When achieving a hierarchy of curricula, students gain greater skills and aptitudes for learning. Bachelorette programs afford different methods of teaching, compared to K-12 programs. Additionally, master's level and doctoral programs require a different level of preparation, commitment, and implementation from students and professors. My contention specifies challenging learners with preeminent, high quality engagement and questioning techniques rather than rote, repetitive methods of teaching. The purpose of this article is to denote effective methods for college teaching, deploring a climate of Socratic questioning, ecological significance implementation, and substantive levels of engagement and feedback.

\section{Pedagogy to Andragogy}

From experience, each level of academia sequentially presents students with more complexity and rigor. Programs gradually ensure higher academic stipulations as students achieve higher academic degrees. Curricula should demonstrate horizontal and vertical articulation as well as continuity so students gradually embrace arduous course requirements.

Besides the change in the methods of teaching, the purpose of teaching for each program (ie. bachelorette, master's, and doctorate) evokes differences in how professors should educate students. Questioning, an education culture, in which seeks to galvanize each learner from philosophical divergence: a caustic assumption, esoteric to the instructor, but however, supports a legal detection in the classroom environment. A vision of the learner is more there as the learner, within the instructor and this, will in turn exercise critical educative properties.

Appropriately, my belief appends that instructors change their philosophy of teaching, so they may internalize these methods and demonstrate an advance level of depth and breadth of instructional-philosophy methods for college students. A change in philosophy denotes an andragogical philosophy of teaching much to the antithesis of pedagogical teaching. Importantly, to initiate a self-evaluation of structural aspects, information-processing norms, thus are purported delineations leading to proficient levels of teaching (Fornaciari, \& Dean, 2014).

Pedagogy, a philosophical premise for teaching and learning, is not student- centered. During which the focus is on the content matter and the stature of the teacher's ability. Many instructors go through a shift in philosophy when beginning college level teaching. As most colleges require K-12 teaching experience for instructor positions, these teachers training is subjective to using subject-centered, child-orientated educational philosophies, which require transformation. Let me make the distinction that pedagogy is not a teaching technique. It is a philosophy that 
examines the foundational goals of teaching and provides clarity when eliciting purpose or meaning (Forrest \& Peterson, 2006). More specifically, how cyclical assumptions of philosophy, theory, and practice interrelate to provide transparency for teaching.

Learners maintain a self-concept within their classrooms. K-12 teachers frame implementation on the assumption that the self-concept of the learner predicates the reservation of external rather than internal resources. Pedagogical norms assert that learners are dependent and reliant from an external presence such as the teacher to specify and deliver to their needs (Thiessen, et al., 2013). For example, students wait for their teachers to present information and direct them to subsequent assignments. The students do not know the destination and aspires for the teacher to provide assistance on getting there.

"Peda" translates as, child, a Greek Lexi, making pedagogy the art and science of teaching children (Sullivan, 2009). On the other hand, "andra" is a form of the word adult, and hence andragogy, in literal interpretation means the art and science of teaching adults. Therefore, depending on the student, and the contextual background of the student, andragogical design curtails towards students that have attained an adult classification. This implication does not pertain to a particular age group, because some students are 16-year-old mothers, or 23-year-old full time graduate students. Providing more clarity, Darkenwald and Merriam (1982) avowed that an adult is someone who has assumed the social primary role of worker, spouse, or parent. The philosophical questions lie whether the precepts of andragogy ought to be an "universal" epistemology for all college students. Due to many students not categorized as adults according to Darkenwald and Merriam, college students ought to benefit from an epigenetic pedagogy?

College instructors require an extensive amount of experience as practitioners in their area of expertise. With this, they are able to provide a valid theoretical perspective from professional practice. Professors with pertinent working experience demonstrate higher utility of variance to their students. As most of them, do prefer learning the curriculum in practical, transparent, and tangible methods. Only providing technical definitions, explanations based on abstract theory, and reliance on text/curricular prompts indicates a lack of thorough, real- world relevance and conviction to students. Instructors with practitioner experience can see potential roadblocks in student learning. This level of awareness could serve as better learning acquisition for students. While making difficult concepts easier to understand, students may perceive and diagnose gaps in learning directly, enhance cognitive intelligence, and prepare a metaphysical synthesis when similar obstacles in learning occur.

My experience purports, contingently, the foundations of effective curricular implementation rest upon the instructor's content level of mastery. Specifically that, effective instructors demonstrate an exhaustive level of expertise in their field: a blend of content pedagogy and practice. In addition, instruction specialists in curriculum apply an etiological and historical conception, recognize the limitations/assumptions in research and implementation, and perceive current and future trends.

For the student, when beginning a course of study, the curriculum in most cases, is unfamiliar and new to them, which sometimes may result in students initially having difficulty making concrete connections and comprehending material. Effective instructors should use previous experiences in pedagogy to gauge students' capacity and current learning levels. Namely, instructors should not oppose and reject their pedagogy conception, but metastasize their endogenous foundations into an andragogical paradigm for teaching and learning. Seeing the rigidness between two philosophies, could limit an instructor's thought processes and decision making for different types of learners. Students' intrinsic processes could benefit from a philosophical hierarchy for learning. With more progressively higher achievement, students necessitate different legal epistemic strategies.

As noted previously, pedagogical assumptions existing, to the self-concept of the learner, equates dependency to assess and delineate needs. Within andragogy, the assumptions for self-concept presume that learners are aware of themselves and their needs. And, therefore, bring this knowledge to the educational activity. For example, students with this knowledge know what type of learner they are, (e.g. visual, auditorial, technical, or kinesthetic); as well as, for some, their intelligence cognition. By knowing this articulation, students are able to master concepts at an efficient rate, resulting in the ability to deepen and expand their conceptualizations. Furthermore, these students bequeath learning situations with a legitimate awareness and absorbed conception above others as they advance in their coursework.

\section{Socratic Questioning}

Socratic type questioning techniques are important for critical thought inter/intra synthesis. Advanced students require qualitative, inquisitive prodding instead of direct closed end questions. As a result, students begin to develop 
their own theories about the world and could therefore incur a deeper sense of learning. Socratic questions are: (1) questions for clarification, (2) questions that probe assumptions, (3) questions that contend reasoning and evidence, (4) questions about viewpoints and perspectives, (5) questions that probe consequence and implications, (6) questions about the question, (Paul,1992). See below for examples of each type of Socratic questions.

\begin{tabular}{|c|c|}
\hline \multicolumn{2}{|c|}{ Questions for clarification } \\
\hline ○ & Why did you say that? \\
\hline ○ & How did you come to this realization? \\
\hline$\circ$ & Are emotional dispositions only detected in an emotional state? \\
\hline \multicolumn{2}{|c|}{ Questions that probe assumptions } \\
\hline$\circ$ & What can we assume instead? \\
\hline o & Is there evidence to confirm or disprove that assumption? \\
\hline ○ & Is there a meso (gray) understanding when assessing degree of difficulty? \\
\hline \multicolumn{2}{|c|}{ Primary and secondary questions that contend reasoning and evidence } \\
\hline$\circ$ & What would be an example? \\
\hline$\circ$ & Is there an analogy you could refer to? \\
\hline$\circ$ & Are socio economic influences related to poor achievement? What is your conception? \\
\hline \multicolumn{2}{|c|}{ Questions about viewpoints and perspectives } \\
\hline$\circ$ & What would be an alternative? \\
\hline ○ & What is the counterargument for ....? \\
\hline$\circ$ & Are all children a result of their environment? \\
\hline \multicolumn{2}{|c|}{ Questions about the question } \\
\hline$\circ$ & What was the aim of this question? \\
\hline ○ & How does... apply to everyday life? \\
\hline$\circ$ & What is this significance or relevance in the real world? \\
\hline
\end{tabular}

Examples of different Socratic questions. Adapted from "Six Types of Socratic Questions," by Paul, R.W., 1992

The higher cognitive and social-emotional developed learner necessitates enigmatic presupposition of Socratic questioning. Questions evoke a complex paradigm while applying a scope of methodology rooted in analytical theory. The advanced students are aware of their extant skills and necessitate an epistemological metaphysical milieu. This looks like a classroom where the professor is an instrument for critical thought. Analogous include: iridescent clouds, blossoming flowers, vile quarry.

Students confide in the constructive criticism of the professor. In most Socratic environments, students value an open dissonance of questioning to further inquire and examine self-interpretation of beliefs. Socratic questions seek to disestablish self-criticism, over analyses the organized, inconformity of the meta physical stage.

\section{Ecological Significance Implementation}

Curriculum \& instructional design incurs a distilled population with ecological relevance. Each lesson and concept requires the instructor to provide a symbiosis of physical (e.g., the built environment, temporal (e.g., time, development) socio- cultural (e.g., values, politics, culture, economic) and organizational characteristics (size, resources, policy, procedures) association (Conye \& Bemak, 2005). My thoughts also contend adding a personal connection to provide explanative delineation. A personal insertion can grasp individual student interests, as well as bring about reflective praxis. An example is when the instructor shares a personal narrative in front of the class. As this, creates a face value, interjecting a valid assessment of the curriculum and self. Moreover, an ecological approach prepares students for social change across all levels of systems and disciplines: in groups, organizations communities, regions, nations, and the world (Kusmawan, O'Toole, Reynolds, \& Bourke, 2009). A versatile thinker who is multi-dimensional could offer a different perspective to the world. As a result, the outcome is a differentiated, 
21-century learner who dismisses narcissistic perpetuations. Derived in lieu of traditional methodology, the effective college instructor harmonizes a learner visionary conception within classrooms. Self-empirical zeal, fosters a direct, infallible resolve of the instructor, and thus confounds the learners. An ecologically centered classroom, fundamentally, is the opposite, focused on creating a dynamic social system, educational and skill- building, (ie. psychoeducational), while promoting interpersonal problem solving, or psychological reshaping \& therapy. Notwithstanding, also embedding is synergism, to convey a learner query in return, is efficacious and infuses a powerful learner centered implication. Adverting silo approaches with an integrated paradigm, eclipses to more general, multidisciplinary and interdisciplinary acquisition. School structure while mostly fragmented to, in a sense drive learners to interconnect curriculum and germane understanding with pragmatics and sequences. While this fosters self-directive intuition, the interior reflective osmosis that veers fleeting, ephemeral teaching and learning is in question.

\section{Substantive Feedback and Engagement}

Substantive feedback is vital for academic growth. Some instructors do not see a positive correlation between feedback and achievement, due to this area being relatively under researched. However, my experience elucidates that feedback as an invisible construct that does greatly impact learning and student efficacy and admonition. My notion precedes students put more value into their products because of the reliability aphorism demonstrated from the instructor. How many departments, for instance, review and analyze instructors written comments on student work? It is important for departments to assess the extent to which instructors substantively engage with a degree of intellectual argument rather than simply commenting on presentation, style, or format (Marsh, Liem, Martin, Morin, \& Nagengast, 2011). Albeit quantitative testing is imperative for accurate utility of institutional fidelity, but without analysis of substantive feedback, it is clearly poor practice.

The merit of performance is carefully and strategically self-imposed and produced by the students. Substantive feedback emerges as implied development, existential conforming, and self-improved immediacy. When the engagement logistics are consistent with course design, students may solicit topics with greater degree of purview. The element of creativity, lucidity, articulation that lacks brevity stimulates right brain congregate, defining the sounds of learning, as effectual and figurate to: whistling, sizzling, and splashing.

\section{Summary}

My views elicit, for most beginning college instructors, to pique inner conscience, examine self-preservation for teaching, and provide an inquisitive forum of learning. A deliberation to mitigate previous pedagogical assumptions could benefit instructors. While some college students requite direct, teacher-centered methodology, opening an ethos for each student, based that each learner is advancing in intellect, and emotional maturity, and thus necessitates a contextual milieu of intuitive creation as well as epistemological resplendence, to investigate self-doubt and ambiguity.

\section{References}

Darkenwald, G.G., \& Merriam, S.B. (1982). Adult education: Foundations of practice. New York, NY: Harper \& Row.

Fornaciari, J.C., \& Dean, L.K. (2014). The $21^{\text {st }}$-century syllabus from pedagogy to andragogy. Journal of Management Education, 38(5), 701-723. http://dx.doi.org/10.1177/1052562913504763

Forrest, P.S., Paul, \& Peterson, O.T. (2006). It's called Andragogy. Academy of Management Learning \& Education, 5(1), 113-122. http://dx.doi.org/10.5465/AMLE.2006.20388390

Kusmawan, U., O’Toole, J.M., Reynolds, R., \& Bourke, S. (2009). Beliefs, attitudes, intentions, and locality: the impact of different teaching approaches on the ecological affinity of Indonesian secondary school students. International Research in Geographical \& Environmental Education, 18(3), 157-169. http://dx.doi.org/10.1080/10382040903053927

Marsh, W.H., Liem, AD, G., Martin, J.A., Morin, J.S.A., \& Nagengast, B. (2011). Methodological measurement fruitfulness of exploratory structural equation modeling (esem): New approaches to key substantive issues in motivation and engagement. Journal of Psychoeducational Assessment, 29(4), 322-346. 


\section{http://dx.doi.org/10.1177/0734282911406657}

Paul, $\quad$ R.W. (1992). Socratic questioning. from http://www.umich.edu/ elements/probsolv/strategy/cthinking.htm

Sullivan, E.L. (2009). The sage glossary of the social \& behavioral sciences. Thousand Oaks, CA: Sage Publication, Inc. http://dx.doi.org/10.4135/9781412972024

Thiessen, D., Campbell, E., Gaztambide-Fern Andez, R., Niyozov, S., Anwaruddin, S., Cooke, C., \& Gladstone, L. (2013). Perspectives on Pedagogy. Curriculum Inquiry, 43(1), 33-44. http://dx.doi.org/10.1111/curi.12006 